\title{
Efficient catenane synthesis by cucurbit[6]uril-mediated azide-alkyne cycloaddition
}

\author{
Antony Wing Hung Ng, Chi-Chung Yee, Kai Wang and Ho Yu Au-Yeung*
}

\section{Full Research Paper}

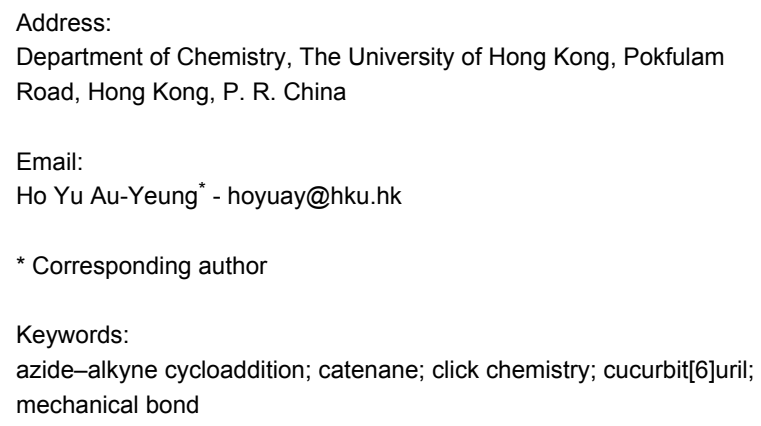

Beilstein J. Org. Chem. 2018, 14, 1846-1853. doi:10.3762/bjoc. 14.158

Received: 12 April 2018

Accepted: 25 June 2018

Published: 20 July 2018

This article is part of the thematic issue "Macrocyclic and supramolecular chemistry".

Guest Editor: M.-X. Wang

(c) $2018 \mathrm{Ng}$ et al.; licensee Beilstein-Institut. License and terms: see end of document.

\begin{abstract}
We report here the efficient synthesis of a series of [3]catenanes featuring the use of cucurbit[6]uril to simultaneously mediate the mechanical and covalent bond formations. By coupling the mechanical interlocking with covalent macrocyclization, formation of topological isomers is eliminated and the [3]catenanes are formed exclusively in good yields. The efficient access to these [3]catenanes and the presence of other recognition units render them promising building blocks for the construction of other high-order interlocked structures.
\end{abstract}

\section{Introduction}

Catenanes are topologically non-trivial molecules possessing mechanically interlocked macrocycles. The flexible but strong mechanical bond between the interlocked macrocycles offers a unique opportunity for exploiting catenanes as molecular machines or new materials with unusual mechanical properties [1-9]. Over the years, different templates and ring-closing reactions to form the interlocked macrocycles have been developed, but the majority of the reported catenanes is limited to the Hopf link (i.e., the simplest [2]catenane with two crossings) [9]. Synthesis of other high-order catenanes with more interlocked macrocycles and/or more crossing points remain challenging and more general synthetic strategies to catenanes are yet to be realized [10-12]. A major challenge in $[n]$ catenane synthesis is the precise spatiotemporal control of the covalent formation of the macrocycles and their mechanical interlocking. Otherwise, various topological isomers such as the non-interlocked products or lower-order catenanes will form, which are detrimental to the synthesis efficiency as well as complicating the purification process [13-19].

One strategy to overcome this challenge is to couple the mechanical bond and covalent bond formation in a single step. If 
the building block preorganization by reversible interactions (which will lead to mechanical interlocking) is also necessary for the covalent bond formation, the covalent trapping of the non-interlocked precursors will be suppressed and the mechanical interlocking of the macrocycles will be ensured. One example is the use of an active metal template, in which the macrocyclization is mediated by the metal ion inside the cavity of a metal-coordinating macrocycle [20]. Cucurbit[6]uril (CB[6]) has also been demonstrated to bind to ammonium-containing azides and alkynes and to mediate their cycloaddition inside the $\mathrm{CB}[6]$ cavity $[21,22]$. Yet, these strategies have been largely limited to the synthesis of rotaxane-based interlocked systems [23], probably because of the additional challenges associated with the macrocyclization in catenane synthesis. Previously, we have reported a preliminary study of a [6]catenane synthesis featuring the $\mathrm{CB}[6]$-mediated azide-alkyne cycloaddition (CBAAC) using phenanthroline-based building blocks [24]. To further explore the applicability and generality of the CBAAC in the construction of mechanically interlocked molecules, we report here the efficient synthesis of a series of [3]catenanes from a combination of different azide and alkyne building blocks. These [3]catenanes were obtained in good yields $(>85 \%)$ with straightforward purification procedures. The good compatibility of CBAAC with these various building blocks and the good yields of the [3] catenanes can serve as an entry point to other high-order $[n]$ catenanes by introducing additional macrocycles through other non-covalent interactions.

\section{Results and Discussion Building block design}

The bis(aminoalkyne) and bis(aminoazide) building blocks used in this study are summarized in Scheme 1. The secondary amines are designed to form ammoniums that will strongly bind to $\mathrm{CB}[6]$ through ion-dipole interactions under aqueous acidic conditions. Upon formation of the inclusion complex with $\mathrm{CB}[6]$, the azide and alkyne functionalities inside the $\mathrm{CB}[6]$ cavity will be placed in close proximity and their cycloaddition will be facilitated. As the cycloaddition is preceded by $\mathrm{CB}[6]$ binding, triazole formation will therefore ensure the interlocking of the $\mathrm{CB}[6]$. A $[1+1]$ macrocyclization of the diazide and dialkyne will then result in the exclusive formation of the [3]catenane with no other topological isomers.

The building blocks contain either a central hexaethylene glycol (HEG) unit or are derived from 1,5-dioxynaphthalene (DN), naphthalenediimide (NDI), 2,9-phenanthroline (Phen) or 4,4'biphenyl (BP) cores which can engage in additional non-covalent interactions, such as metal-ligand coordination, charge transfer, $\pi$-stacking and hydrophobic interactions, for the later interlocking of additional macrocycles to give higher-order $[n]$ catenanes. The new building blocks were synthesized following similar procedures as previously described [24].

\section{Catenane synthesis by CBAAC Synthesis of [3]catenanes}

The CBAAC-mediated [3]catenane synthesis was first investigated using the dioxynaphthalene building blocks DN-N3 and DN-CC. Different from the previously reported [3] catenane Cat-0 which is derived from DN-N3 and Phen-CC [24], both DN-N3 and DN-CC contain the flexible ethylene glycol linkers between the terminal azide and alkyne groups, so that any other possible preorganization effects, except that of the ammonium binding to $\mathrm{CB}[6]$ could be eliminated to study the efficiency of CBAAC in the catenane formation. In our first trial, a 1:1:2 mixture of DN-N3, DN-CC and CB[6] in $0.2 \mathrm{M} \mathrm{HCl}$ was heated at $70{ }^{\circ} \mathrm{C}$ and the reaction mixture was analyzed by LC-MS. After heating for 1 hour, although a peak corresponding to the $[1+1]$ cyclized product with $m / z$ values consistent with the [3]catenane Cat-1 could be observed, some unreacted building blocks and unidentified products were also found. Further extending the reaction time to 3,5 or 8 hours resulted in similar chromatograms with no significant improvement of the yield of Cat-1. A similar observation has been reported in a CBAAC-mediated rotaxane synthesis and additional templates have been used to positively cooperate with the $\mathrm{CB}[6]$ binding to the ammoniums on the building blocks to improve the efficiency of CBAAC [23]. In view of the low solubility of $\mathrm{CB}[6]$ and the possibility of thermal-assisted azide-alkyne cycloaddition of the unbound building blocks that may lead to the incomplete cycloaddition and other side products, we decided to first assemble a pseudo[3] rotaxane $\mathrm{CB}[6]$ complex with either the azide or alkyne building block, before introducing the other building block to the reaction mixture. By heating a solution of DN-N3 in the presence of two equivalents of $\mathrm{CB}[6]$ in $0.2 \mathrm{M}$ aq $\mathrm{HCl}$ for 2 hours, a clear solution was formed that indicated $\mathrm{CB}[6]$ dissolution and formation of the inclusion complex. One equivalent of DN-CC was added and the mixture was further heated at $70{ }^{\circ} \mathrm{C}$. LC-MS analysis of the reaction mixture showed that the building blocks were completely consumed after one hour of heating, and that the crude mixture contained the [3]catenane Cat-1 as the major product with $>85 \%$ yield (Scheme 2). Using DN-CC to first form the pseudo[3]rotaxane $\mathrm{CB}[6]$ complex did not affect the efficiency of CBAAC and Cat-1 was obtained in a similar yield. These results show that the initial formation of the pseudorotaxane complex helps the CBAAC by avoiding any cycloadditions outside of the $\mathrm{CB}[6]$ cavity and that CBAAC can be an efficient strategy for catenane synthesis.

Cat-1 and its interlocked nature were further characterized by $\mathrm{MS}^{2},{ }^{1} \mathrm{H}$ and ${ }^{13} \mathrm{C}$ NMR spectroscopy. The $\mathrm{PF}_{6}{ }^{-}$salt of Cat-1 

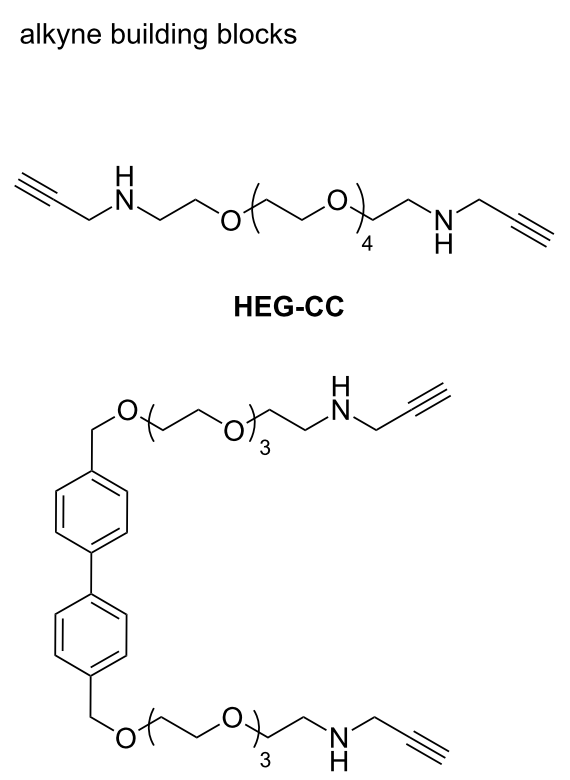

BP-CC<smiles>C#CCNCCOCCOc1cccc2c(OCCOCCOCC#C)cccc12</smiles>

DN-CC<smiles></smiles>

Phen-CC

azide building blocks<smiles>NCCNCCOCCOc1cccc2c(OCCOCCNCCN)cccc12</smiles>

DN-N3<smiles>N#CCCNCCOCCOCc1ccc(-c2ccc(COCCOCCNCCN)cc2)cc1</smiles>

BP-N3<smiles></smiles>

Phen-N3<smiles>N#CCCNCc1ccc(OCCOCCOc2ccc(CNCCOCCN3C(=O)c4ccc5c6c(ccc(c46)C3=O)C(=O)N(CCCOc3ccccc3)C5=O)cc2)cc1</smiles>

NDI-N3

Scheme 1: Diazide and dialkyne building blocks used in this study.

was isolated in $69 \%$ yield as a white solid by precipitation with a saturated $\mathrm{NH}_{4} \mathrm{PF}_{6}$ solution and simple filtration. The ESIMS spectrum showed two peaks at $m / z=808.5$ and 1076.3, consis- tent with the $3+$ and $4+$ ions of Cat-1. Similar to Cat-0, the $\mathrm{MS}^{2}$ spectrum of Cat-1 revealed $\mathrm{CB}[6]$-bound fragments, showing the strong $\mathrm{CB}[6]-$ ammonium interactions are 


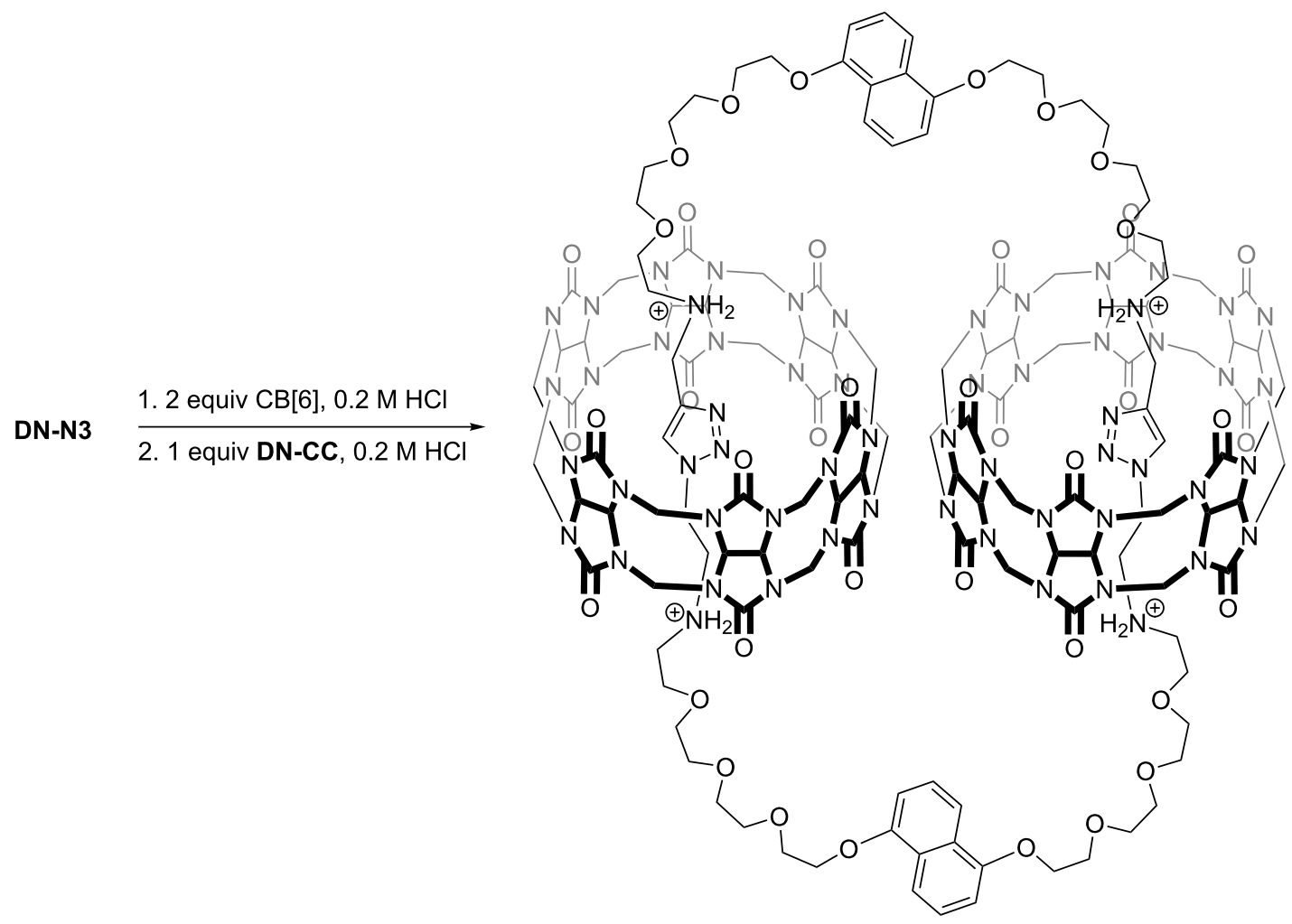

Cat-1, $85 \%^{\mathrm{a}}, 69 \%^{\mathrm{b}}$

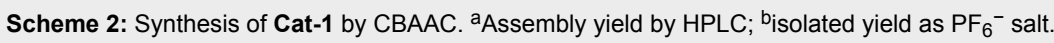

preserved under the MS conditions. Inclusion of the triazole in the $\mathrm{CB}[6]$ cavity was evidenced by the upfield shifted triazole resonance from $8.5 \mathrm{ppm}$ to $6.4 \mathrm{ppm}$ when compared with that of free triazole in non-interlocked system [22,24,25]. NOE cross peaks between the triazole and $\mathrm{CB}[6]$ protons were also observed. The ${ }^{1} \mathrm{H}$ NMR spectrum of Cat-1 showed one set of aromatic resonances, suggesting the chemical environments of two dioxynaphthalene units are highly similar and that Cat-1 is adopting a symmetrical conformation in solution, consistent with the tight binding of the diammonium to the $\mathrm{CB}[6]$ and the overall flexibility of the [3]catenane structure.

With the success of CBAAC in the efficient synthesis of Cat-1, nine other [3]catenanes (Cat-2-Cat-10) were synthesized from different combinations of the alkyne and azide building blocks under similar conditions (Scheme 3). In all cases, LC-MS analysis of the crude reaction mixtures showed the complete consumption of the building blocks with the [3]catenane as the only major product with yields $>85 \%$. This demonstrates not only the high efficiency of CBAAC in catenane synthesis, but also the good compatibility of CBAAC with various types of building blocks. Because of the high yields of these [3]catenanes, their isolations were all straightforward. Cat-2-Cat-10 were isolated either by precipitation as the $\mathrm{PF}_{6}{ }^{-}$salts or by preparative HPLC, and were fully characterized by MS, NMR and UV-vis spectroscopy. Similar to Cat-1, the upfield shifted triazole ${ }^{1} \mathrm{H}$ NMR resonances of Cat-2-Cat-10 at ca. $6.4 \mathrm{ppm}$ are consistent with the inclusion of the triazole in the $\mathrm{CB}[6]$ cavity $[22,24,25]$. The ESIMS, HRMS and $\mathrm{MS}^{2}$ spectra are all consistent with the [3] catenanes with a similar fragmentation behavior as that of Cat-1. The ${ }^{1} \mathrm{H}$ NMR, ${ }^{13} \mathrm{C}$ NMR and ESIMS spectra of Cat-2-Cat-10 are shown in Figure 1 and Figure 2, and in Supporting Information File 1, Figures S29-S55 and S60-S68.

With the different combinations of the additional recognition units (i.e., DN, NDI, Phen and BP) in these [3]catenanes, other macrocycles/building blocks that could favorably interact with these units could be introduced to give higher-order catenanes with multiple interlocked rings. As a preliminary study of highorder $[n]$ catenane assembly using this approach, CBAAC of BP-N3 and DN-CC was repeated in the presence of 10 equiva- 
<smiles>C#CCNCc1ccc(CNCC#C)cc1</smiles><smiles>N#CCCNCc1ccc(CNCCN)cc1</smiles>

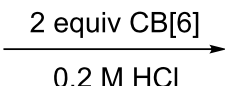

$0.2 \mathrm{M} \mathrm{HCl}$

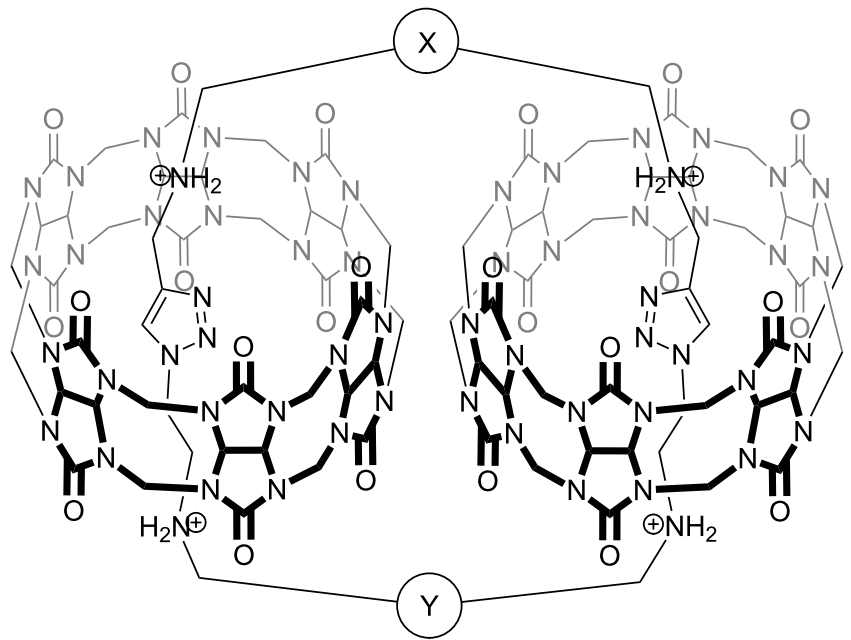

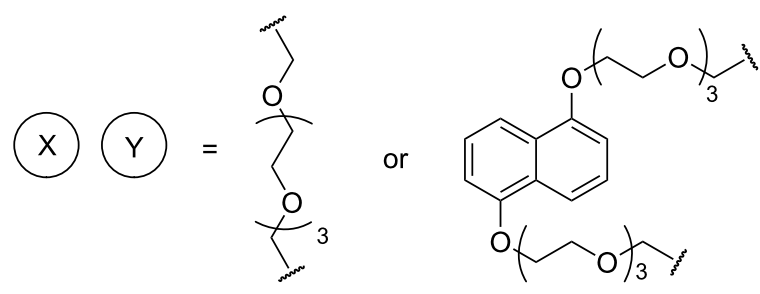

or<smiles>Ic1ccc(OCc2ccc3ccc4ccc(COc5ccc(I)cc5)nc4c3n2)cc1</smiles>

or<smiles>CC(C)(C)OCCOCc1ccc(-c2ccc(COCCOC(C)(C)C)cc2)cc1</smiles><smiles>COCCOc1ccc(I)cc1</smiles>

\begin{tabular}{lllll} 
& azide & alkyne & yield \\
\hline Cat-0 [24] & DN-N3 & Phen-CC & $85 \%^{\mathrm{a}}$ & $(66 \%)^{\mathrm{b}}$ \\
Cat-1 & DN-N3 & DN-CC & $85 \%^{\mathrm{a}}$ & $(69 \%)^{\mathrm{b}}$ \\
Cat-2 & NDI-N3 & DN-CC & $92 \%^{\mathrm{a}}$ & $(65 \%)^{\mathrm{c}}$ \\
Cat-3 & BP-N3 & DN-CC & $85 \%^{\mathrm{a}}$ & $(75 \%)^{\mathrm{c}}$ \\
Cat-4 & NDI-N3 & BP-CC & $93 \%^{\mathrm{a}}$ & $(74 \%)^{\mathrm{c}}$ \\
Cat-5 & BP-N3 & BP-CC & $89 \%^{\mathrm{a}}$ & $(62 \%)^{\mathrm{c}}$ \\
Cat-6 & BP-N3 & Phen-CC & $88 \%^{\mathrm{a}}$ & $(60 \%)^{\mathrm{c}}$ \\
Cat-7 & DN-N3 & HEG-CC & $89 \%^{\mathrm{a}}$ & $(65 \%)^{\mathrm{b}}$ \\
Cat-8 & NDI-N3 & HEG-CC & $91 \%^{\mathrm{a}}$ & $(64 \%)^{\mathrm{b}}$ \\
Cat-9 & BP-N3 & HEG-CC & $92 \%^{\mathrm{a}}$ & $(67 \%)^{\mathrm{b}}$ \\
Cat-10 & Phen-N3 & HEG-CC & $85 \%^{\mathrm{a}}$ & $(59 \%)^{\mathrm{b}}$
\end{tabular}

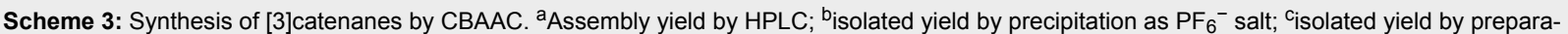
tive HPLC.

lents of $\beta$-cyclodextrin ( $\beta$-CD), which is known to form a stable inclusion complex with the BP unit due to hydrophobic effects $\left(K_{\mathrm{a}} \approx 7 \times 10^{3} \mathrm{M}^{-1}\right.$ in $\left.\mathrm{D}_{2} \mathrm{O}\right)$ [26] (Scheme 4). To our delight, a [4]catenane (Cat-11) was obtained in $60 \%$ yield along with $30 \%$ of Cat-3. Of note, due to a much weaker binding between the 1,5-dioxynaphthalene unit and $\beta$-CD [26,27], no [5]catenane was observed. ESIMS and $\mathrm{MS}^{2}$ spectra of Cat-11 are consistent with the inclusion of one $\beta-\mathrm{CD}$ (and two $\mathrm{CB}[6]$ ). The ${ }^{1} \mathrm{H}$ NMR spectrum showed a slight upfield shift of the BP protons to 7.61 and $7.48 \mathrm{ppm}$ when compared with that of
Cat-3 at 7.75 and $7.54 \mathrm{ppm}$. These observations are all consistent with a [4]catenane structure with the BP unit being included in the cavity of the $\beta-C D$, which is further supported by the appearance of the BP protons as two broad signals due to their slightly different chemical environment inside the $\beta-C D$ (Supporting Information File 1, Figure S56). Together with our previous demonstration of the compatibility of CBAAC with $\mathrm{Cu}^{+}$-phenanthroline coordination in a [6]catenane assembly, the successful synthesis of Cat-11 shows the feasibility of using CBAAC with a versatile selection of building blocks and non- 


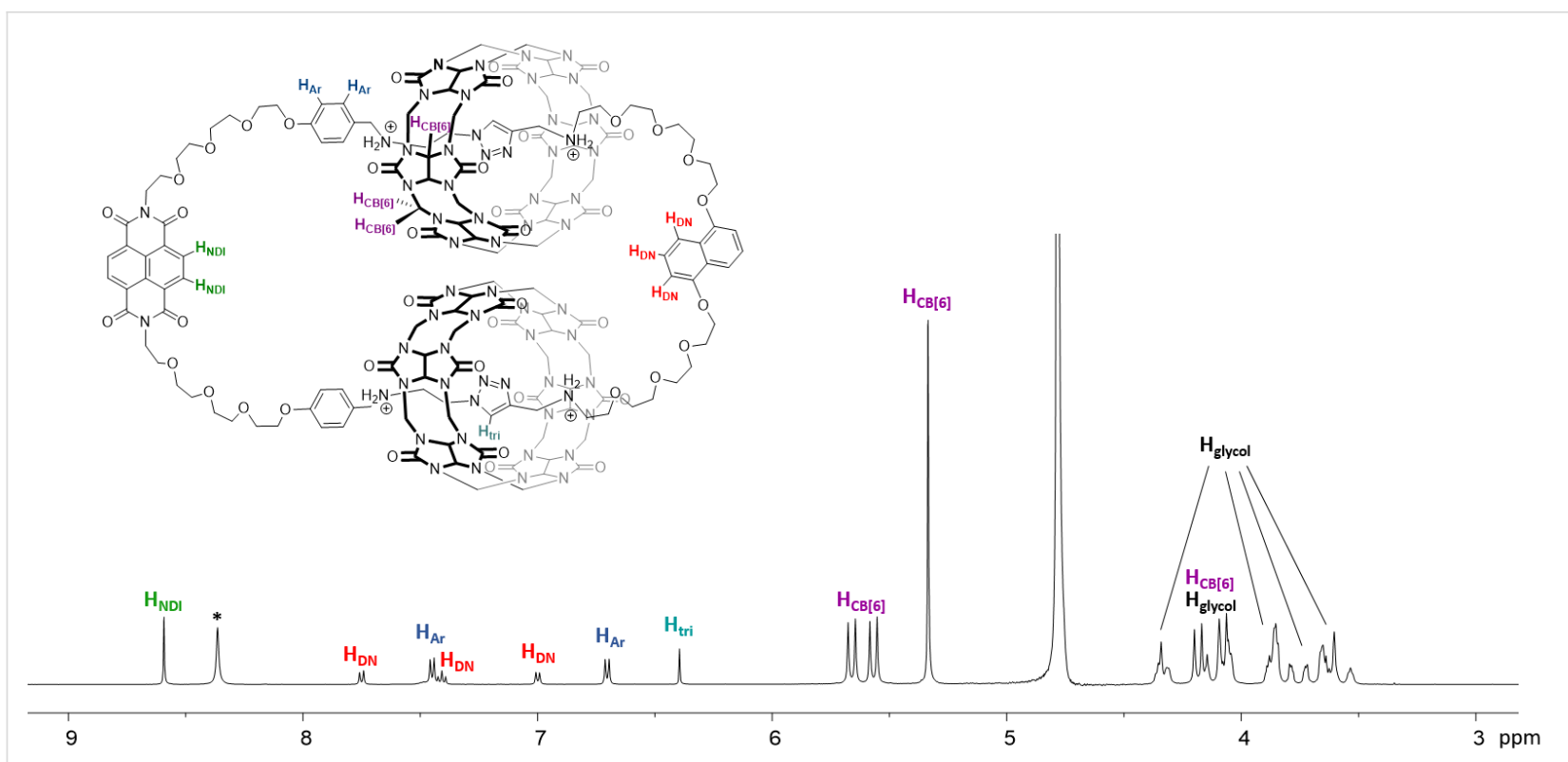

Figure 1: ${ }^{1} \mathrm{H}$ NMR $\left(500 \mathrm{MHz}, \mathrm{D}_{2} \mathrm{O}, 298 \mathrm{~K}\right)$ of Cat-2. The signal at ca. $8.3 \mathrm{ppm}$ is the residual formate from preparative HPLC.

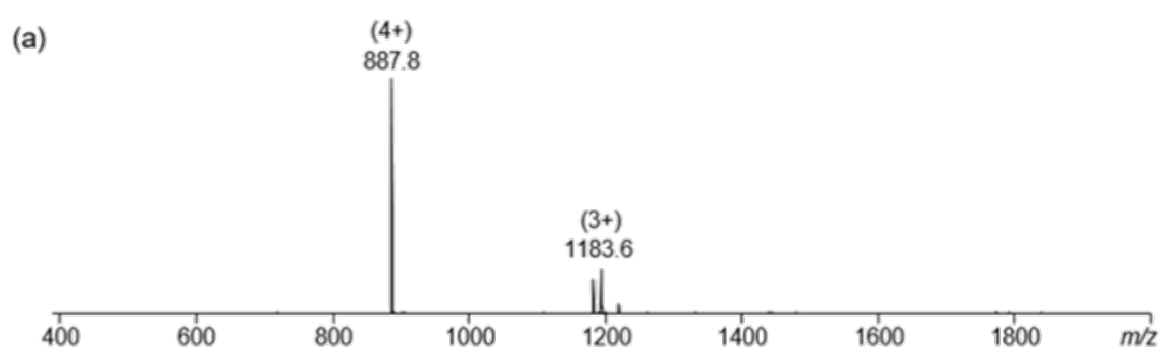

(b)
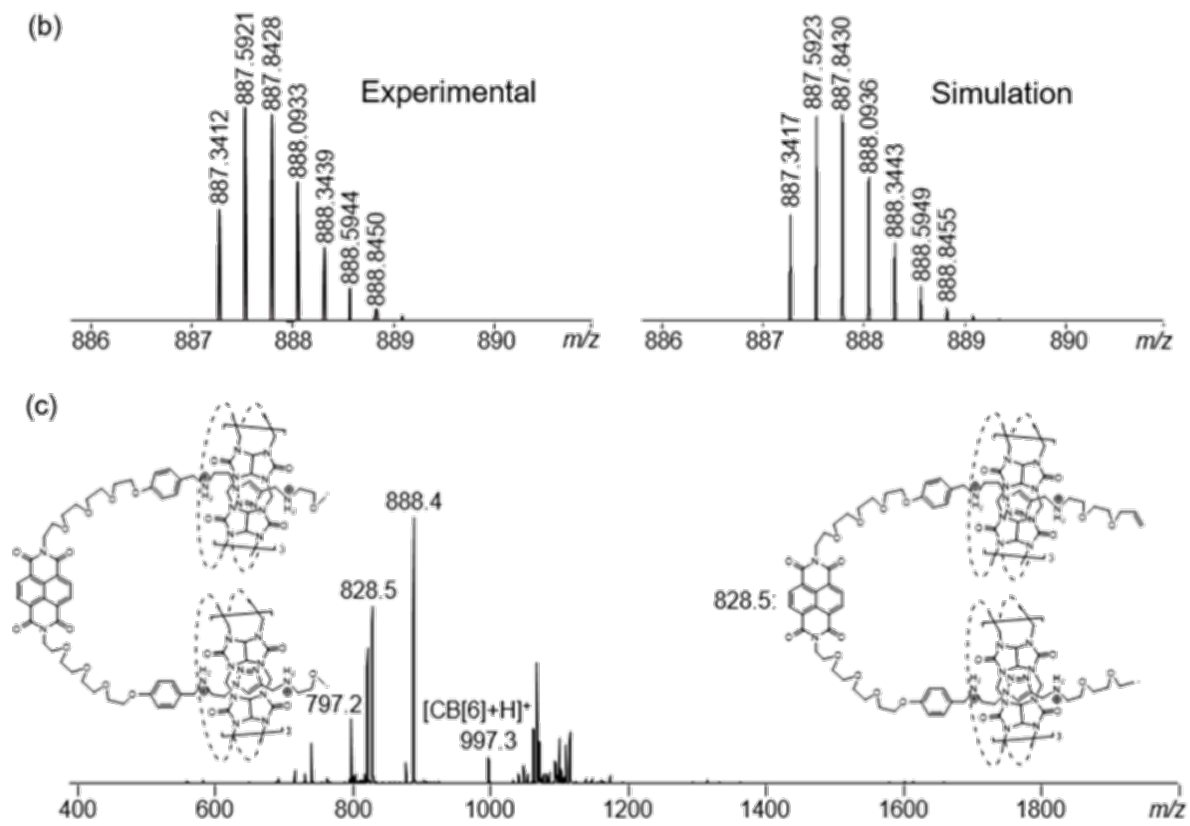

Figure 2: (a) ESIMS, (b) HRMS, and (c) $M^{2}$ spectrum (parent ion at $\mathrm{m} / \mathrm{z}=887.8$ ) of Cat-2. 


\section{DN-CC $\frac{1.2 \text { equiv } \mathrm{CB}[6], 0.2 \mathrm{M} \mathrm{HCl}}{2.1 \text { equiv BP-N3, } 10 \text { equiv } \beta-\mathrm{CD},}$ $0.2 \mathrm{M} \mathrm{HCl}$}

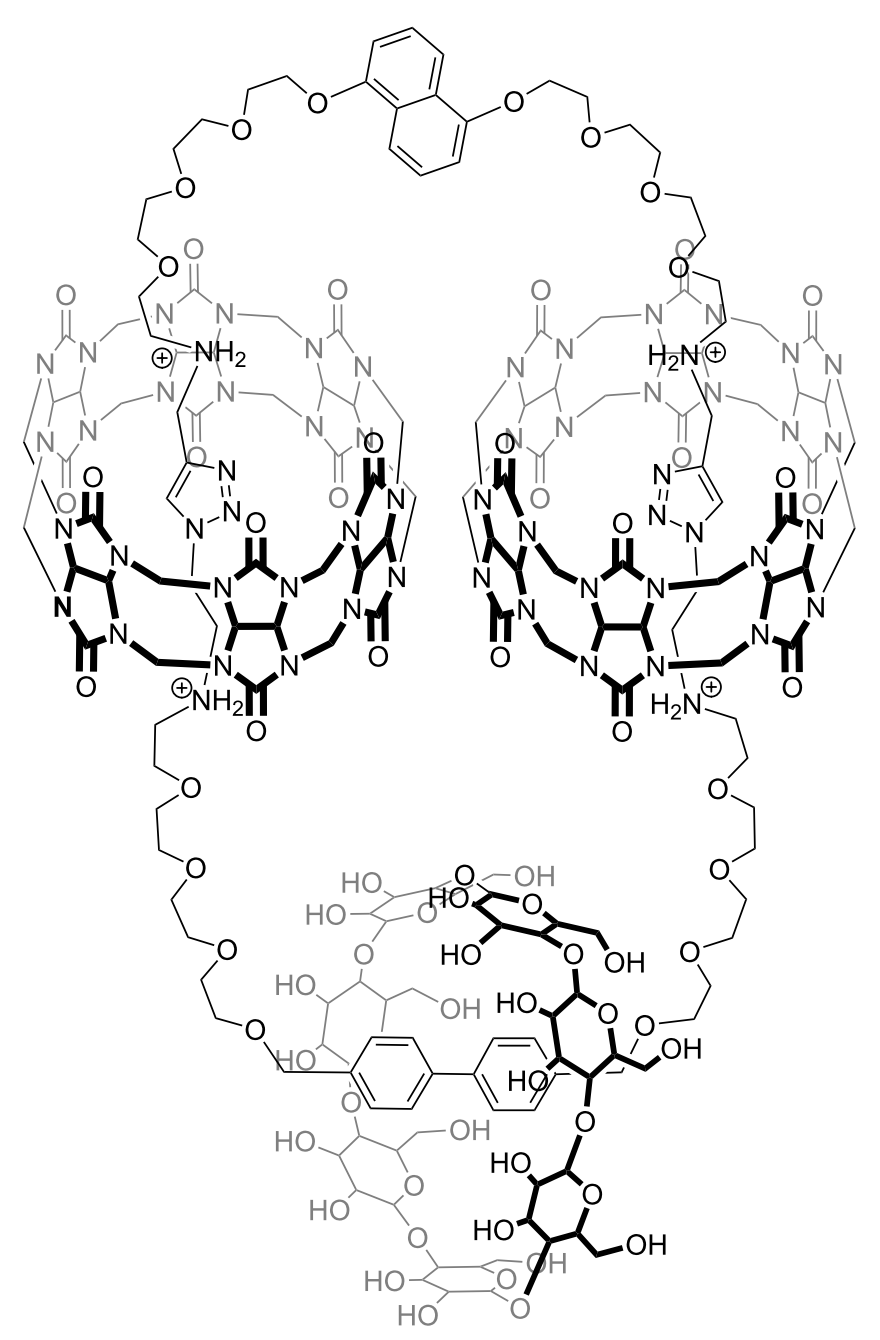

Cat-11, 60\% $\%^{\mathrm{a}}, 45 \%^{\mathrm{b}}$

Scheme 4: Synthesis of the [4]catenane Cat-11. aAssembly yield by HPLC; bisolated yield by preparative HPLC.

covalent interactions to construct complex high-order $[n]$ catenanes.

\section{Conclusion}

In summary, the use of CBAAC in the efficient [3]catenane syntheses is described. Ten new [3]catenanes and a [4]catenane were obtained in a simple one-pot procedure. The key feature of this strategy is that the use of $\mathrm{CB}[6]$ couples the mechanical interlocking with the covalent macrocycle formation, so that the catenanes were formed exclusively with no formation of other topological isomers. This CBAAC strategy is versatile and building blocks containing various recognition units can be used, therefore offering a convenient entry point to access more complex high-order catenanes with multiple interlocked macrocycles.

\section{Supporting Information}

\section{Supporting Information File 1}

Detailed experimental procedures and characterization data (MS, $\mathrm{MS}^{2},{ }^{1} \mathrm{H}$ and ${ }^{13} \mathrm{C} \mathrm{NMR}$ and $\mathrm{UV}$-vis spectra).

[https://www.beilstein-journals.org/bjoc/content/ supplementary/1860-5397-14-158-S1.pdf]

\section{Acknowledgements}

The work described in this paper was supported by the Croucher Foundation and a grant from the Research Grants Council of the Hong Kong Special Administrative Region, China (Early Career Scheme, Project No. HKU 27300014). AWHN, CCY and KW are recipients of the Postgraduate Schol- 
arship from The University of Hong Kong. We acknowledge UGC funding administered by The University of Hong Kong for support of the Electrospray Ionization Quadrupole Time-ofFlight Mass Spectrometry Facilities under support for Interdisciplinary Research in Chemical Science.

\section{ORCID ${ }^{\circledR}$ iDs}

Antony Wing Hung Ng - https://orcid.org/0000-0002-9279-9918 Ho Yu Au-Yeung - https://orcid.org/0000-0002-7216-7921

\section{References}

1. Sauvage, J.-P. Acc. Chem. Res. 1998, 31, 611-619. doi:10.1021/ar960263r

2. Nepogodiev, S. A.; Stoddart, J. F. Chem. Soc. Rev. 1998, 98, 1959-1976. doi:10.1021/cr970049w

3. Erbas-Cakmak, S.; Leigh, D. A.; McTernan, C. T.; Nussbaumer, A. L. Chem. Rev. 2015, 115, 10081-10206. doi:10.1021/acs.chemrev.5b00146

4. Evans, N. H.; Beer, P. D. Chem. Soc. Rev. 2014, 43, 4658-4683. doi:10.1039/c4cs00029c

5. Dietrich-Buchecker, C. O.; Sauvage, J. P. Chem. Rev. 1987, 87, 795-810. doi:10.1021/cr00080a007

6. Fang, L.; Olson, M. A.; Benítez, D.; Tkatchouk, E.; Goddard, W. A., III; Stoddart, J. F. Chem. Soc. Rev. 2010, 39, 17-29. doi:10.1039/B917901A

7. Beves, J. E.; Blight, B. A.; Campbell, C. J.; Leigh, D. A.; McBurney, R. T. Angew. Chem., Int. Ed. 2011, 50, 9260-9327. doi:10.1002/anie.201007963

8. Forgan, R. S.; Sauvage, J.-P.; Stoddart, J. F. Chem. Rev. 2011, 111, 5434-5464. doi:10.1021/cr200034u

9. Gil-Ramírez, G.; Leigh, D. A.; Stephens, A. J. Angew. Chem., Int. Ed. 2015, 54, 6110-6150. doi:10.1002/anie.201411619

10. Niu, Z.; Gibson, H. W. Chem. Rev. 2009, 109, 6024-6046. doi: $10.1021 / \mathrm{cr} 900002 \mathrm{~h}$

11. Raehm, L.; Hamilton, D. G.; Sanders, J. K. M. Synlett 2002, 1743-1761. doi:10.1055/s-2002-34860

12. Wu, Q.; Rauscher, P. M.; Lang, X.; Wojtecki, R. J.; de Pablo, J. J.; Hore, M. J.; Rowan, S. J. Science 2017, 358, 1434-1439. doi:10.1126/science.aap7675

13. Amabilino, D. B.; Ashton, P. R.; Boyd, S. E.; Lee, J. Y.; Menzer, S.; Stoddart, J. F.; Williams, D. J. Angew. Chem., Int. Ed. Engl. 1997, 36, 2070-2072. doi:10.1002/anie.199720701

14. Bitsch, F.; Dietrich-Buchecker, C. O.; Khemiss, A. K.; Sauvage, J. P.; Van Dorsselaer, A. J. Am. Chem. Soc. 1991, 113, 4023-4025. doi:10.1021/ja00010a072

15. Li, S.; Huang, J.; Zhou, F.; Cook, T. R.; Yan, X.; Ye, Y.; Zhu, B.; Zheng, B.; Stang, P. J. J. Am. Chem. Soc. 2014, 136, 5908-5911. doi:10.1021/ja502490k

16. Langton, M. J.; Matichak, J. D.; Thompson, A. L.; Anderson, H. L. Chem. Sci. 2011, 2, 1897-1901. doi:10.1039/c1sc00358e

17. Iwamoto, H.; Tafuku, S.; Sato, Y.; Takizawa, W.; Katagiri, W.; Tayama, E.; Hasegawa, E.; Fukazawa, Y.; Haino, T. Chem. Commun. 2016, 52, 319-322. doi:10.1039/C5CC07562A

18. Black, S. P.; Stefankiewicz, A. R.; Smulders, M. M. J.; Sattler, D.; Schalley, C. A.; Nitschke, J. R.; Sanders, J. K. M. Angew. Chem., Int. Ed. 2013, 52, 5749-5752. doi:10.1002/anie.201209708
19. Au-Yeung, H. Y.; Yee, C.-C.; Ng, A. W. H.; Hu, K. Inorg. Chem. 2018, 57, 3475-3485. doi:10.1021/acs.inorgchem.7b02523

20. Crowley, J. D.; Goldup, S. M.; Lee, A.-L.; Leigh, D. A.; McBurney, R. T. Chem. Soc. Rev. 2009, 38, 1530-1541. doi:10.1039/b804243h

21. Tuncel, D.; Özsar, Ö.; Tiftik, H. B.; Salih, B. Chem. Commun. 2007, 1369-1371. doi:10.1039/B616764K

22. Sinha, M. K.; Reany, O.; Yefet, M.; Botoshansky, M.; Keinan, E. Chem. - Eur. J. 2012, 18, 5589-5605. doi:10.1002/chem.201103434

23. Ke, C.; Smaldone, R. A.; Kikuchi, T.; Li, H.; Davis, A. P.; Stoddart, J. F. Angew. Chem., Int. Ed. 2013, 52, 381-387. doi:10.1002/anie.201205087

24. Wang, K.; Yee, C.-C.; Au-Yeung, H. Y. Chem. Sci. 2016, 7, 2787-2792. doi:10.1039/C5SC04774A

25. Celtek, G.; Artar, M.; Scherman, O. A.; Tuncel, D. Chem. - Eur. J. 2009, 15, 10360-10363. doi:10.1002/chem.200901504

26. Armspach, D.; Ashton, P. R.; Ballardini, R.; Balzani, V.; Godi, A.; Moore, C. P.; Prodi, L.; Spencer, N.; Stoddart, J. F.; Tolley, M. S.; Wear, T. J.; Williams, D. J. Chem. - Eur. J. 1995, 1, 33-55. doi:10.1002/chem.19950010109

27. It has been reported that the bindings of a methylated derivative of $\beta-C D$ to 1,5-dioxynaphthalene derivatives were at least two order-of-magnitude weaker than that of the bindings to biphenyl guests. See reference [26] for details.

\section{License and Terms}

This is an Open Access article under the terms of the Creative Commons Attribution License (http://creativecommons.org/licenses/by/4.0). Please note that the reuse, redistribution and reproduction in particular requires that the authors and source are credited.

The license is subject to the Beilstein Journal of Organic Chemistry terms and conditions: (https://www.beilstein-journals.org/bjoc)

The definitive version of this article is the electronic one which can be found at: doi: $10.3762 /$ bjoc. 14.158 